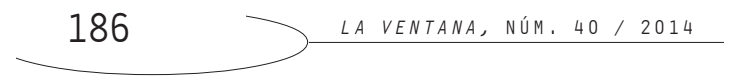

\title{
Igualdad de género, poder y comunicación: las mujeres en la propiedad, dirección y puestos de toma de decisión ${ }^{1}$
}

\section{Aimée Vega Montiel}

${ }^{1}$ Este artículo forma parte de la investigación en progreso: "Igualdad de género, poder y comunicación. La influencia de las mujeres en los procesos de toma de decisión en las industrias de comunicación", coordinada por la autora de este artículo y financiada por el Programa PAPIIT-UNAM. Este artículo fue posible gracias a la valiosa colaboración de Daniela Esquivel, Gabriela Hernández, Alejandra Ruiz y Zaira Ramos becarias del proyecto.

\section{Resumen}

Con base en la perspectiva feminista de la economía política de la comunicación y en evidencias cuantitativas, el objetivo de este artículo es analizar la participación de las mujeres en los niveles de propiedad, dirección y puestos de toma de decisión en las industrias de comunicación en México.

Palabras clave: Mujeres, industrias de comunicación, propiedad, dirección, toma de decisión

\begin{abstract}
Based on the feminist perspective on the political economy of communication as well as on quantitative data, the goal of this paper is to analyze the women's participation in Mexican media industries, as owners, managers, including their participation in decision making processes.
\end{abstract}

Keywords: Women, Media Industries, Ownership, Management, Decision-making. 
RECEPCIÓN: 31 DE ENERO DE 2013 / ACEPTACIÓN: 3 DE JULIO DE 2014

Si vas caminando en las instalaciones de cualquier medio de comunicación, la primera persona con la que te toparás, probablemente será una mujer: la recepcionista, la asistente personal. Si tu cita es en el área de comercialización o relaciones públicas, su representante tal vez será una mujer. Pero si te diriges al área de operación técnica, seguramente verás a 15 o 20 hombres antes de toparte con una mujer. Si el objeto de tu visita es presentar la propuesta de un nuevo programa al área ejecutiva, las probabilidades de que el representante de esa área sea un hombre, son cinco o seis veces mayores de que se trate de una mujer. Y si vas a la Dirección General, tus posibilidades de encontrar a una mujer son mínimas: de todas las grandes empresas de comunicación (en Europa), sólo una cuenta con una Directora General. El resto, cuenta con hombres.

MARgaret Gallagher (1990).

\section{Introducción}

De acuerdo con el Foro Económico Mundial de 2010, México ocupa el lugar 91, de 134, en igualdad de género (WEF, 2010). Las mujeres constituyen el $36.5 \%$ del total de personas empleadas y el 63\% de la población analfabeta (Monroy, 2010). La representación 
política de las mujeres en ambas cámaras del Congreso es del 24\%. En los últimos 30 años, sólo cinco mujeres han gobernado algún Estado de la República y sólo una ha encabezado el gobierno de la Ciudad de México. El 82.8\% de las niñas ayuda a hacer la comida en sus casas, mientras que sólo el $11.8 \%$ de los niños lo hace. El $85.8 \%$ de niñas lavan y planchan ropa, frente al 14.2\% de niños que lo hace (Informe Nacional sobre Violencia de Género en la Educación Básica en México, SEP, 2010).

Al tratarse de un problema estructural, la desigualdad de género se replica en todas las instituciones sociales, lo cual supone el principal obstáculo para alcanzar la universalidad de los derechos humanos.

Una de las instituciones centrales que permitirían a las mujeres realizar derechos esenciales tales como la libertad, la equidad, la igualdad, la inclusión y la participación en el espacio público, son los medios de comunicación. En este sentido, referirse a su derecho humano a comunicar implica no sólo promover una representa-

${ }^{2}$ El Derecho Humano a Comunicar se encuentra establecido en el artículo 19 de la Declaración Universal de los Derechos Humanos que expresa que Toda persona tiene derecho a expresarse, a ser escuchada, a ser reconocida, a ser proyectada con dignidad, a recibir información con base en la transparencia, la diversidad, la participación y la justicia social y económica. ción adecuada de las mujeres en los contenidos, y de su poder como agentes sociales, sino reconocer e impulsar su plena participación en las industrias de comunicación como propietarias, directoras y creadoras. $^{2}$

Sin embargo, en México el panorama es poco alentador. En el país, domina una alta concentración del sector en pocos actores. De acuerdo con los datos recabados por la investigación que da lugar a este artículo, el 93\% de las 
industrias privadas de televisión, son de Televisa y Televisión Azteca, el $67 \%$ de la industria radiofónica es privada y la mayor parte de estas estaciones son propiedad de 15 grupos. Asimismo, el 70\% del sector de las telecomunicaciones se encuentra controlado por Telmex (CNN Expansión, 2011). Este crecimiento ha ido acompasado por la ausencia de una ley de medios democrática, necesaria para garantizar la apertura y diversidad del sistema audiovisual y de telecomunicaciones.

Por ello, el sistema comunicativo es considerado como un obstáculo para la democracia en México. En el renglón de los contenidos, estas empresas reproducen imágenes que vulneran los derechos humanos de las mujeres y que lejos están de promover su ciudadanía. Ello encuentra razón en la falta de pluralidad de la estructura del sistema audiovisual, que manifiesta una notable inequidad, no sólo en el nivel de la propiedad, sino en el de la dirección y la producción de contenidos. Y es éste el contexto que en México condiciona la realización del derecho humano de las mujeres a comunicar.

Por ello, se considera fundamental preguntar: ¿Son los medios de comunicación aliados de los derechos humanos de las mujeres? ¿Promueven el acceso y participación de las mujeres en sus sistemas de propiedad, dirección y en la toma de decisiones? De esta pregunta parte el análisis que a continuación se expone y que incluye los datos relacionados con el sistema concesionado (privado) de radio y televisión en México, así como con la industria periodística. 


\section{Diálogo entre Feminismo y}

\section{Economía Política de la Comunicación}

Para estudiar la relación de las mujeres con las industrias de comunicación, en términos de su acceso y participación, es preciso identificar las intersecciones entre Feminismo y Economía Política de la Comunicación.

¿Por qué con la Economía Política de la Comunicación? Porque ha sido un campo útil para comprender la importancia de las industrias de comunicación en el capitalismo global. Focalizando una parte central del análisis en los procesos de propie-

${ }^{3}$ Las industrias culturales son definidas como sistemas de producción, distribución y consumo de bienes simbólicos (Wasko, 2005; Bolaño, Mastrini y Sierra, 2005). dad y control de las industrias culturales, ${ }^{3}$ y en sus implicaciones políticas, la Economía Política ha permitido dar cuenta de la forma en cómo estas industrias determinan la producción cultural en la sociedad (Wasko, 2005).

Al ser objeto de una alta concentración, las industrias culturales han tenido implicaciones severas en el desarrollo democrático de las sociedades, implicaciones que van más allá del ámbito económico, afectando el orden político, social y cultural (Bolaño, Mastrini y Sierra, 2005). En este sentido, se reconoce el poder de estas agencias en la producción social de significados, y por tanto, en la definición de visiones hegemónicas del mundo (Gómez, 2008).

De acuerdo con Janet Wasko (2005), las industrias de comunicación se definen por cuatro características: 
1. Son identificadas como bienes de consumo, puesto que crean y distribuyen productos y servicios.

2. Forman parte de un amplio proceso de diversificación, dado que son propiedad de empresas que compiten en otros sectores, además del mediático.

3. Manifiestan una integración horizontal, al lado de otras compañías del mismo sector; pero también una integración vertical, puesto que han sumado a sus conglomerados a otras compañías para hacer funcionar su larga cadena de producción y distribución.

4. Accionan en sinergia con otras empresas del sector, lo que les permite maximizar beneficios.

Ante ello, el análisis de los sistemas de medios requiere de una perspectiva integral que apunte al estudio de los sistemas de control y propiedad, pero también a la producción y los contenidos.

La crítica feminista a la Economía Política, se enfoca en la neutralidad genérica de su análisis — neutralidad basada en la visión masculina del mundo- - La EP ha ignorado la naturaleza genérica del capitalismo, invisibilizando la posición y situación de las mujeres en el sistema capitalista.

La asociación exclusiva de la injusticia a la desigualdad de clase, ha puesto un velo sobre el hecho de que la desigualdad de género es la primera forma de discriminación social, sobre la cual se montan las de clase, raza, sexualidad y nacionalidad (Byerly y Ross, 2006). ${ }^{4}$

${ }^{4}$ De acuerdo con Ellen Riordan (2002), esto sucede porque el materialismo histórico privilegió el análisis de la división del trabajo, de la posición de clase y de 
la explotación, sin tomar en cuenta la opresión de las mujeres en el sistema patriarcal.
En este contexto, se hace necesario acompasar el concepto de injusticia no sólo con desigualdades económicas, sino con jerarquías de estatus y asimetrías de poder político. Es imperativo, establece Nancy Fraser, remplazar la visión economicista de la justicia por una visión amplia, tridimensional, que articule economía, cultura y política. ¿Cómo? Politizando lo personal, ampliando el significado de justicia y evidenciando como injusticias sociales acciones que han sido toleradas históricamente (Fraser, 2009).

De esta manera, al colocar en el centro del análisis la Teoría de Género, la Economía Política Feminista ha permitido identificar que

${ }^{5}$ Una importante acotación hecha por la teoría feminista, es que la variable de género no sirve si se le usa de manera aislada, sino y sólo al lado de indicadores sociales que incluyan sexo, clase, raza, etnia, edad, etcétera, y en relación al contexto socio-histórico, a fin de advertir diferencias más profundas (Riordan, 2002). el patriarcado y el capitalismo son dos estructuras que, en conjunto, generan condiciones de desigualdad de género. ${ }^{5}$ Este acierto ha permitido ir más allá en la conceptualización del capitalismo como el sólo proceso de las relaciones de clase en la acumulación de capital. En el campo de los estudios de comunicación, la perspectiva feminista ha logrado evidenciar que, no sólo la forma en la cual las industrias de comunicación representan al sujeto femenino, sino también las prácticas de consumo, y las experiencias de las mujeres que trabajan en esas organizaciones, son producto del capitalismo patriarcal que valora las formas masculinas de organización y conocimiento (Byerly y Ross, 2006).

Estas formas generan condiciones que obstaculizan el desarrollo pleno del derecho humano de las mujeres a comunicar, y replican la injusticia y la opresión en otras esferas. 
Producto del diálogo con la Economía Política, lo que podemos denominar como la Economía Política Feminista de la Comunicación (EPFC) (Riordan, 2002), aporta datos muy ilustrativos de la marginación y discriminación de las mujeres en las industrias de comunicación, como propietarias, trabajadoras (esto es, editoras, reporteras, periodistas) y creadoras (como cineastas, productoras y directoras):

En Estados Unidos, sólo el 9 por ciento de mujeres dirige alguna empresa pequeña de telecomunicaciones o de comercio electrónico; en Europa, sólo el 12 por ciento de los puestos ejecutivos son ocupados por mujeres (Byerly y Ross, 2006).

En Estados Unidos, las mujeres constituyen apenas el 24 por ciento de directoras de televisión y 20 por ciento de radio (US-based Radio-Television News Directors Association and Foundation, 2001, en Lauer 2002).

De acuerdo con el Global Report on the Status of Women in the News Media (2011), el 73\% de los directores de la industria periodística en el mundo son hombres y sólo el 27\% son mujeres. En el nivel de la producción periodística, los hombres concentran dos tercios de los puestos de trabajo como periodistas y reporteros, comparado con el 36\% que ocupan las mujeres.

- El acoso sexual y el sexismo son problemas que las periodistas identifican como dominantes en estas institucio- 
nes: en Estados Unidos, entre el 40 y el 60 por ciento de las periodistas han sido objeto de acoso sexual, mientras que en Inglaterra, el 40 por ciento ha sido objeto de comentarios degradantes y de ataques físicos.

${ }^{6}$ En el patriarcado, el poder implica dominio y sujeción de los hombres sobre las mujeres. Al poder patriarcal se le reconoce como el conjunto de capacidades que permiten controlar la vida de una mujer y de someterla, de expropiarle recursos materiales y simbólicos. En concreto, trata de la institucionalización del dominio masculino sobre las mujeres en el contexto amplio de la sociedad (Lerner, 1990)
El origen de esta marginación, encuentra su explicación en la desigual distribución del poder que priva en las relaciones de género, y en la inequidad y opresión que ello origina. ${ }^{6}$ Revisemos a continuación la situación que priva en el contexto mexicano.

\section{Metodología}

Siguiendo la perspectiva metodológica de la Economía Política Feminista de la Comunicación (Byerly, 2011; Byerly y Ross, 2006), en la investigación que da origen a este artículo, sobre el acceso y participación de las mujeres en las industrias de comunicación en México, se incluyen tres grandes dimensiones que nos permiten identificar los niveles de estas industrias en los que laboran las mujeres:

- 1) Macro, asociado al sistema de propiedad, puestos de dirección, administración y de toma de decisión de las industrias de comunicación. 
2) Meso, que incluye los niveles profesional y técnico y a las mujeres en su trabajo como reporteras, productoras, creadoras, técnicas, etcétera.

3) Micro, nivel que permite acercarse a la experiencia individual de mujeres que han trabajado en estas industrias, e identificar los límites y posibilidades asociados a su desarrollo.

Asimismo y con el fin de identificar los niveles particulares que se hallan en estas dimensiones, recurrimos a la propuesta incluida en el Global Report on the Status of Women in the News Media (2011). En lo relativo al nivel Macro, que es el que reporta este artículo, las autoras lo dividen en: Propiedad, Gobierno y Dirección de alto nivel.

El método para recoger estos datos ha sido cuantitativo y nos ha permitido construir el mapa, parte del cual se expone a continuación y que nos muestra la participación de las mujeres en el nivel Macro de las industrias televisiva, radiofónica y de la prensa en México.

Debemos señalar que la construcción de los datos no ha sido tarea sencilla, pues parte característica del sistema antidemocrático de medios que persiste en México, es la falta de transparencia en la información que las industrias hacen pública respecto a su estructura, hecho que convive con la falta de rigurosidad de las instituciones y autoridades correspondientes en exigir que la información consignada por dichas organizaciones sea completa y veraz. 
Así, el primer paso consistió en tomar como fuente la información que la entonces Comisión Federal de Telecomunicaciones (Cofetel), hizo pública entre los años 2011 y 2013, respecto a las titularidades de concesiones y permisos de radio y televisión en el país.

Puesto que dicha información arrojó resultados pobres y heterogéneos, el siguiente paso consistió en solicitar la información a las propias televisoras y radiodifusoras acerca de su sistema de propiedad, así como de la conformación de sus consejos de administración y de su planta laboral. Las industrias privadas no aprobaron nuestra solicitud. A las públicas accedimos vía solicitudes de acceso a la información pública, mismas que la mayoría respondió, aunque de forma incompleta pues no siempre incluyeron la totalidad de su planta laboral. Finalmente, los portales de estas empresas en Internet constituyeron una fuente más para construir el mapa que nos propusimos.

En cuanto a la información de la prensa, nuestro rastreo respondió a la búsqueda precisa del nombre, sexo y cargo tanto de mujeres como de hombres que laboran en periódicos impresos. Por ello, la accesibilidad a la publicación impresa fue uno de los criterios principales de la investigación.

Para revisar los impresos página por página se recurrió a instancias oficiales, así como a medios electrónicos de acceso público. Esto permitió contar con una visión institucional y otra no regulada de las publicaciones impresas.

Entre las fuentes oficiales se atendió a la Secretaría Técnica de la Comisión Calificadora de Publicaciones y Revistas Ilustradas 
(CCPRI), encargada de clasificar y registrar las publicaciones y revistas ilustradas de edición periódica que circulan en el país. Se acudió de manera presencial a revisar los ejemplares impresos de diarios autorizados por la SEGOB a partir de 2004 y hasta abril de 2012.

Otra base de datos útil fue el Padrón Nacional de Medios Impresos (PNMI), una herramienta pública en línea, que de forma voluntaria registra periódicos, revistas, encartes y suplementos, etcétera. para certificar su distribución y circulación periódica, así como el tipo de público que los lee. Contiene en promedio 900 publicaciones, de las cuales poco más de la mitad corresponde a diarios.

En dichas visitas oficiales, la información recabada fue insuficiente, pues en algunos casos no se encontraron los ejemplares o su contenido estuvo incompleto (sobre todo en el PNMI). Además, estas instancias carecen de atribuciones legales para generar un registro obligatorio de periódicos y muchos medios impresos coexisten sin registro de licitud ni interés comercial por la publicidad del gobierno federal. Por ello, se empleó un criterio más para tener un panorama más completo de periódicos: la búsqueda de periódicos en Internet.

Con todo ello, pudimos obtener un registro más completo del acceso y participación de las mujeres en la industria privada de radio y televisión, así como de la prensa en México.

En este artículo, hemos incluido el análisis derivado de una serie de entrevistas a mujeres que han ocupado puestos estratégicos 
en algunos medios de comunicación y que nos ayudan a entender lo que hay detrás de los datos cuantitativos. Esta dimensión de la investigación, que es de orden cualitativo, está en una fase temprana; sin embargo, no quisimos dejar de incluir algunos de sus testimonios en este artículo.

\section{Hallazgos: Las mujeres en el sistema de medios en México}

\section{Las mujeres en los niveles de propiedad y gobierno}

El sistema de medios en México se caracteriza por el alto nivel de concentración de la industria audiovisual en muy pocos grupos. De acuerdo con los resultados obtenidos en nuestra investigación, el 93 por ciento de la televisión comercial abierta es controlada por Televisa y Televisión Azteca, empresas que a su vez operan en otros

\section{Gráfica 1. Distribución de concesiones de televisión en México}

\section{Total de magistrados de circuito y jueces de distrito designados $2008-2009$}

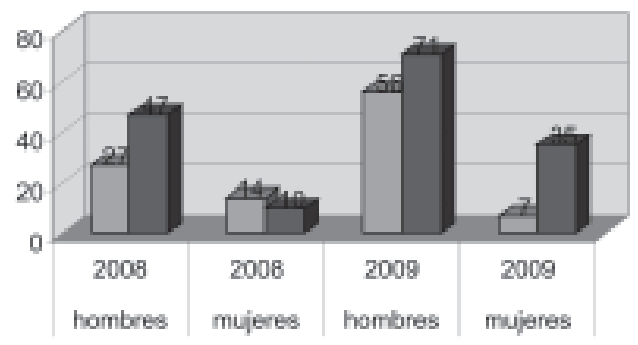

Fuente: Elaboración propia. 
niveles de la industria más amplia de medios, telecomunicaciones y del entretenimiento -medios impresos, telefonía celular, televisión por cable, música, deportes, cine, teatro, etcétera.

El sector radiofónico repite la misma tendencia: el 67 por ciento de las radios, son concesionadas y la mayoría de ellas son propiedad de 15 grupos.

En el sector de la prensa, más del 25 por ciento de los más de 500 diarios que circulan en el país son propiedad de 9 grupos.

\section{Gráfica 2. Distribución de espectro*}
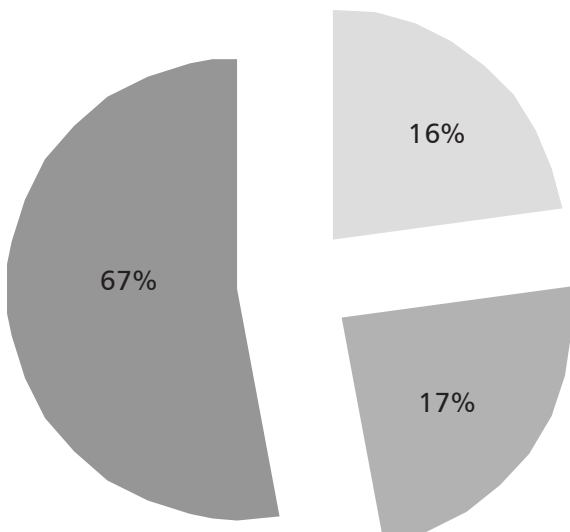

En proceso de instalación**

Permisionado

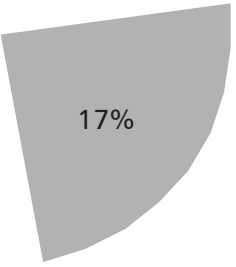

Concesionado

* 1,882 estaciones: 1,257 concesiones, 322 permisos y 303 en proceso de instalación.

** Cofetel no determina la naturaleza de estas estaciones, sólo anota este término.

Fuente: Elaboración propia. 


\section{Gráfica 3. Concentración de la industria periodística en México}

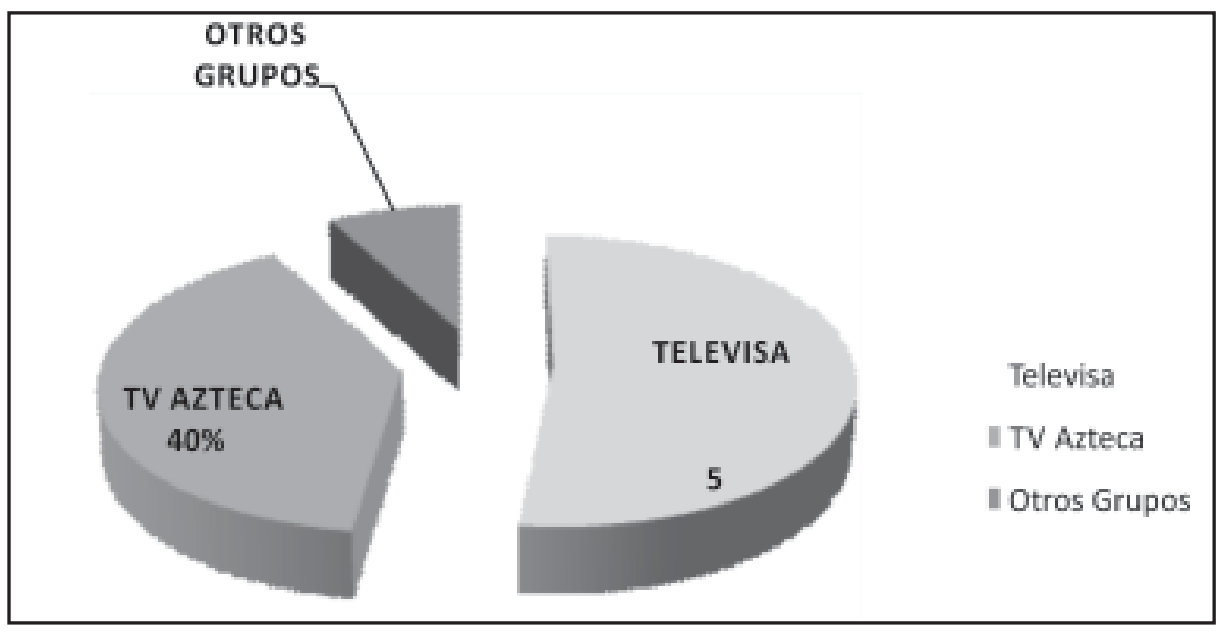

Fuente: Elaboración propia.

¿Y quién ostenta la propiedad de estos medios? Como se verá a continuación, la brecha de género define la marginación de las mujeres en el sistema comunicativo en México.

En la industria televisiva, las mujeres no constituyen más del $1 \%$ de quienes tienen la titularidad de una concesión, todas asociadas a la empresa Televisa. Además, debemos señalar que la mayor parte de los títulos de concesión de estaciones de televisión en México, no están registrados a nombre de personas sino de razones sociales, lo que imposibilita conocer la identidad de los propietarios reales de los medios.

En la radiofónica, las mujeres constituyen apenas el 13\% del total de los propietarios. En este punto, hay que tomar en cuenta 


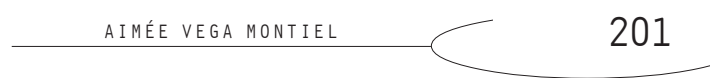

que, puesto que la mayor parte de las concesiones de radio son propiedad de 15 grupos o familias, varias de las titularidades que figuran como propiedad de alguna mujer, lo son por herencia, lo que significa que probablemente figuran como prestanombres pero que no ejercen poder como las propietarias reales.

En el caso de la industria periodística, la exclusión es contundente: ninguna mujer figura como propietaria de alguno de los principales grupos que controlan el sector en México.

A la vista de estos datos, podemos corroborar que la marginación de las mujeres en el sistema de propiedad de medios de comunicación en México, replica la misma tendencia de marginación que experimentan en otras esferas. En este punto, y siguiendo los presupuestos de la Economía Política Feminista de la Comunicación, dicha exclusión sucede en un marco definido por el androcentrismo que domina el mundo de las relaciones sociales y económicas. No es aventurada entonces la hipótesis de Karen Ross y Carolyn Byerly (2006), cuando señalan que la industria de los medios constituye uno de los tentáculos más poderosos del poder patriarcal.

\section{Las mujeres en el nivel del gobierno}

Los datos disponibles en este renglón, permiten afirmar que el nivel de gobierno y el control de puestos estratégicos para la toma de decisiones en las industrias de comunicación, evidencia una clara desigualdad de género.

De acuerdo con los datos que recabamos, el consejo de administración de Grupo Televisa está conformado por 38 hombres, quie- 


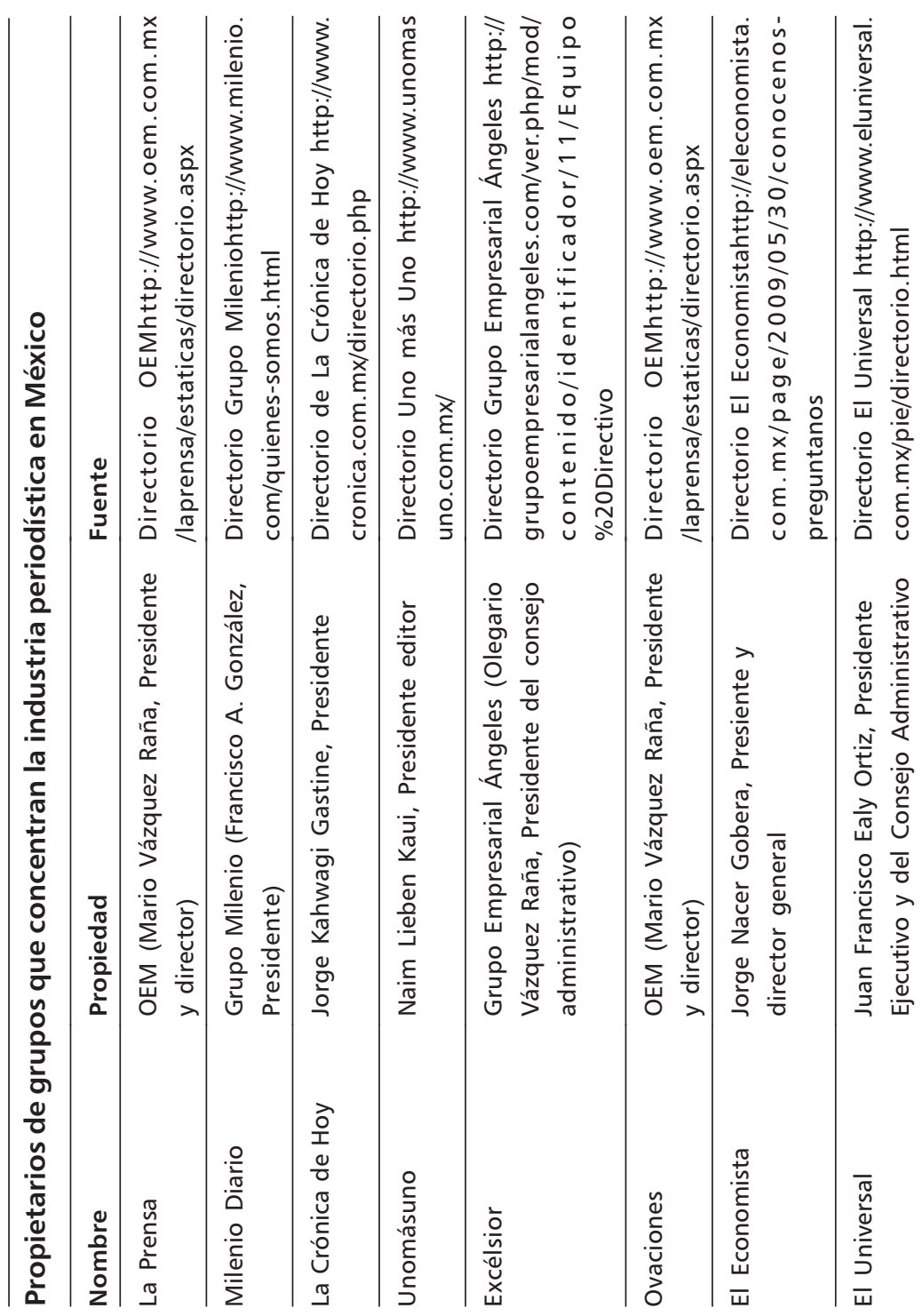




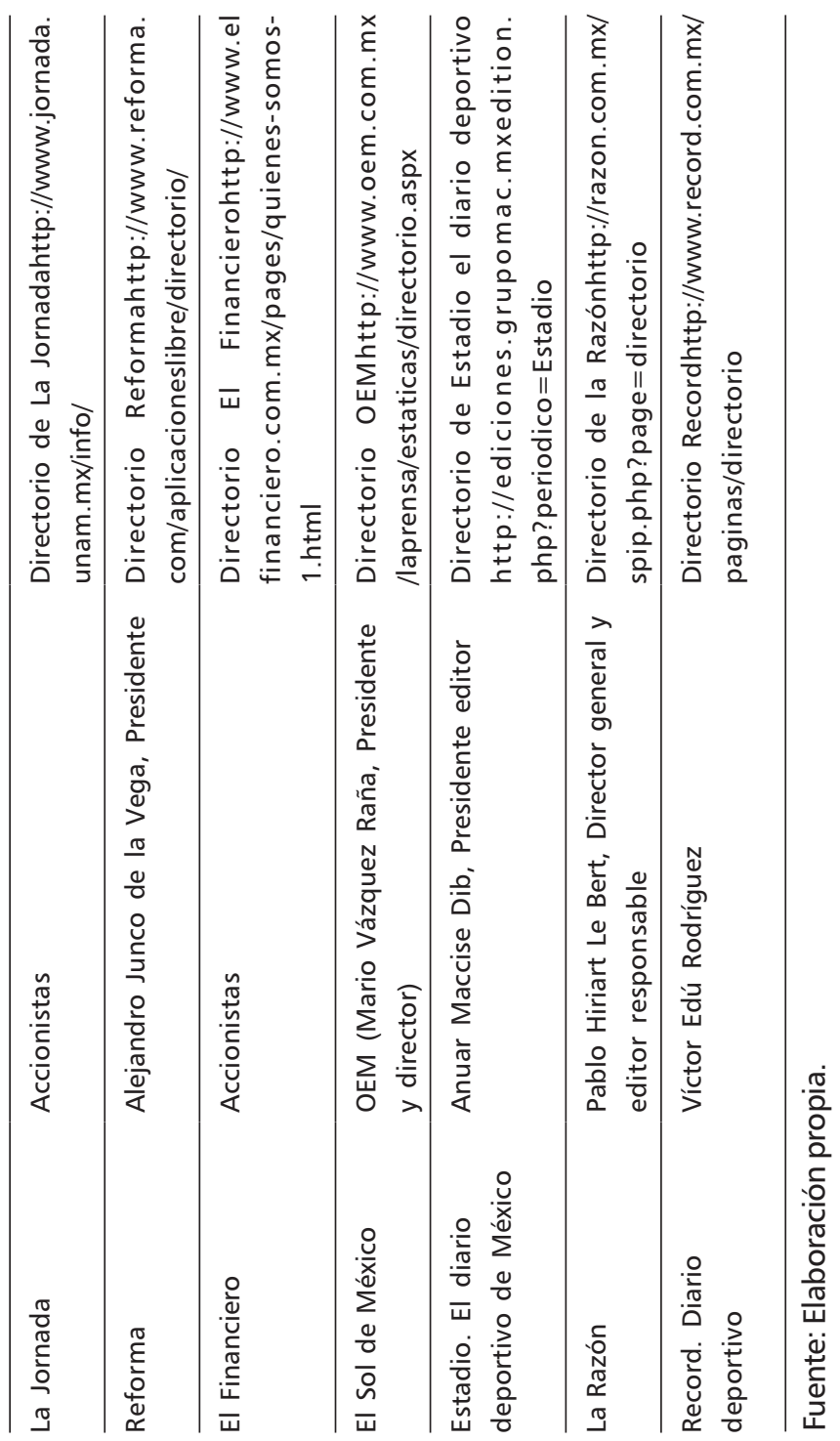


nes toman decisiones acerca de la administración y los contenidos de las concesiones operadas por este grupo. Televisión Azteca tiene un consejo de administración constituido por 14 hombres, que deciden igualmente sobre todas sus concesiones. Y otros dos grupos privados, IMAGEN Multimedia y Multimedios Televisión, S.A. de C.V., tienen consejos de administración conformados también y exclusivamente por hombres.

En el caso de la industria radiofónica, las mujeres constituyen apenas el 8\% de quienes ocupan cargos en los consejos de administración, cifra que se reduce al 5\% cuando analizamos su participación en el nivel de la presidencia de estas concesiones.

Y en prensa, sólo el 11\% de quienes participan en la toma de decisiones a nivel del gobierno, son mujeres.

¿Qué implicaciones tiene esto para el desarrollo de una comunicación promotora de la igualdad de género? Que, al quedar marginadas de los lugares estratégicos de estas industrias, las mujeres no tienen ningún poder de influencia sobre las decisiones que en materia de administración y contenidos mediáticos se toman. Ello repercute en la reproducción de los estereotipos sexistas en los contenidos que ha denunciado ampliamente la academia feminista, y desde luego, tiene efectos perniciosos sobre la ciudadanía de las mujeres y su participación plena en el espacio público.

\section{Las mujeres en la dirección de alto nivel de los medios}

La dirección de alto nivel incluye a todas las personas que se desempeñan en puestos ejecutivos de estas empresas, y que incluyen 
la dirección general, dirección editorial, dirección de finanzas y dirección de administración, entre los más importantes. En este nivel se manifiesta la misma tendencia: muy pocas mujeres cuentan con el poder de dirigir y tomar decisiones relacionadas con la operación, políticas y finanzas de las industrias de comunicación en México.

En el sistema de televisión privada, ninguna mujer se desempeña como alta ejecutiva ni en alguno de los puestos de dirección de alto nivel. En la industria radiofónica, las mujeres constituyen el $11 \%$ de quienes dirigen alguna de las áreas estratégicas de este sector. Y en la prensa, sólo ocupan el 13\% de los cargos, mientras que el resto, el $87 \%$, son administrados por hombres.

A la vista de lo expuesto, afirmamos que la marginación femenina en los sistemas de propiedad, toma de decisiones y dirección de las industrias de comunicación en México, no es un mero accidente, sino producto de la opresión originada por el capitalismo patriarcal, y que en el contexto de la globalización ha vuelto más aguda la desigualdad de género.

Estos datos evidencian que el sector de los medios en México se encuentra controlado: 1) por pocos actores y 2) principalmente hombres. Este problema tiene distintas implicaciones. Observamos que, al no acceder de manera plena a las industrias de comunicación como propietarias, las mujeres quedan marginadas de uno de los sectores más importantes del capitalismo global: las industrias culturales.

En este tenor, su poder de influencia en las formas culturales que circulan en la sociedad — los contenidos— es mínimo. Por lo 
tanto, la posibilidad de erradicar los estereotipos sexistas que dominan en los productos culturales, y que se encuentran en la base de la discriminación y la violencia de género es, hasta hoy, nula. Sin embargo, no dejamos de insistir en la necesidad de impulsar la participación paritaria de las mujeres en estas industrias —en la propiedad, la producción y la decisión sobre la administración y los contenidos-, condición para que, al lado de otras acciones, ayuden a realizar su derecho humano a comunicar.

Expuestos así, estos datos evidencian la clara expresión del poder patriarcal en el terreno de las industrias culturales. Desde luego, es muy probable que, en la vida cotidiana, las mujeres que logran acceder a las industrias de medios, construyan estrategias afirmativas para impulsar derechos comunicativos que beneficien a todas las mujeres, pero es muy probable también que lo tengan que hacer en condiciones de desventaja; condiciones expresadas en la discriminación y la violencia de género de las que otras investigaciones han dado cuenta (Byerly y Ross, 2006).

En este punto, queremos sumar otra fase de esta investigación que contempla entrevistas a profesionales de la comunicación, que han desarrollado actividades en los medios como propietarias, directoras, tomadoras de decisiones, productoras, creadoras y periodistas. Aunque el avance en este rubro es todavía incipiente, nos parece importante referir los testimonios de algunas de estas mujeres, pues nos ayudan a dar sentido a los datos cuantitativos aquí descritos.

En lo que estas profesionales coinciden, es en el hecho de que las mujeres que logran acceder a las industrias de comunicación, 
se enfrentan a muchas barreras que dificultan e incluso impiden su desarrollo. Estos obstáculos los adjudican a su condición de género, es decir, al hecho de ser mujeres.

Algunos de los principales problemas, son:

- La violencia verbal y el acoso sexual, perpetrado por los periodistas contra sus colegas, o contra mujeres que tienen una posición inferior en la jerarquía del medio. En este punto, una periodista afirma: es común que llegue "algún compañero a tu redacción y te haga bromas sexistas[...] o acose a alguna compañera "auxiliar" porque se cree con más poder porque es reportero [...]. Se suele utilizar todavía la palabra "viejas" para referirse a cuestiones de mujeres, o se trata según lo "guapa" o "fea" que sea esa reportera".

— La masculinización de las prácticas de trabajo, que obligan a las mujeres a asumir rutinas creadas para los hombres (en términos de fuentes, temas y horarios). En este renglón, se reconoce que algunas mujeres que logran ascender en la estructura del medio, reproducen los principios y las rutinas masculinas, para mantenerse en la profesión.

— La desigualdad que el reconocimiento y la remuneración económica del trabajo realizado por las mujeres recibe. En este punto, en promedio y de acuerdo con los testimonios recogidos, las mujeres perciben un 30\% menos del salario que reciben sus pares hombres por realizar el 
mismo trabajo, lo que la mayoría de veces no se evidencia en la nómina oficial del medio, pero sí en compensaciones extra como bonos y bienes.

El techo de cristal, objetivado en la experiencia de las mujeres que logran un progreso notable para colocarse en la industria, pero que nunca alcanzan las posiciones de dirección y decisión. Las razones que comúnmente les impiden alcanzar o mantenerse en los puestos de poder, se encuentran asociadas a su condición de género — ser madres o esposas.

La marginación de las mujeres de algunas áreas de trabajo, consideradas como "masculinas". Es el caso, en México, de las áreas técnicas de los medios audiovisuales operación, iluminación, musicalización, edición, etcétera-, en donde no se contrata a mujeres, al ser consideradas tareas que sólo pueden ser desempeñadas por hombres. Lo mismo sucede en la producción televisiva o en el periodismo gráfico, terreno en el que se identifica que a pesar de que hoy la tecnología ha hecho mucho más livianos los equipos, son los hombres quienes ocupan la mayoría de puestos de camarógrafos y fotógrafos”.

Estos problemas, aislados o en su conjunto, motivan que algunas mujeres profesionales de los medios opten por trabajar por cuenta propia, dado el desgaste físico y emocional que les representa desarrollarse en un universo masculino. 
Para cerrar este trabajo, debo señalar que este tema importa, e importa mucho. Primero, porque es una cuestión de justicia social el impulsar el acceso paritario y en condiciones de igualdad de las mujeres en todas las esferas de la sociedad. Y segundo, porque los medios son, al lado de la familia y la escuela, una de las instituciones de socialización más importantes. Tan sólo en México, el 97\% de la población se informa o se entretiene a través de los programas de Televisa y Televisión Azteca. Las niñas y los niños consumen un promedio de cinco horas diarias de televisión. Y los productos que circulan por estos medios están muy lejos de impulsar los derechos humanos y políticos de las mujeres. Por ello es que apostamos por la paridad, porque en la medida en que esto suceda, las mujeres podrán introducir nuevas perspectivas en las cartas programáticas de los medios y se abrirían posibilidades para la diversidad y la calidad en los medios de comunicación.

\section{Conclusiones}

Consideramos que la consolidación de la democracia en México no podrá darse mientras sigan existiendo condiciones de desigualdad y marginación en el acceso de las mujeres a los medios de comunicación como propietarias, directoras y tomadoras de decisiones.

Algunas acciones que consideramos necesarias y que enlisto a continuación, ayudarían a promover la realización del derecho humano de las mujeres a comunicar en nuestro país: 
Es urgente una regulación que impulse un sistema de concesión que garantice la plena participación de las mujeres en la propiedad, gobierno, dirección y producción en medios de comunicación.

- En la evaluación para otorgar una nueva concesión, debería considerarse el criterio de la discriminación positiva de género, con el objetivo de que las redes de mujeres productoras tengan garantizado su derecho a concursar por una concesión.

_- Es necesario incrementar el acceso de las mujeres a recursos financieros y tecnológicos para desarrollar plenamente sus capacidades comunicativas.

\section{Bibliografía}

Bolaño, César; Guillermo Mastrini y Francisco Sierra (eds.). Economía política, comunicación y conocimiento. Una perspectiva crítica latinoamericana, Buenos Aires, La crujía, 2005.

Byerly, Carolyn y Karen Ross. Women and Media, A critical Introduction. London, Blackwell, 2006.

Byerly, Carolyn (2011). Global Report on the Status of Women in the News Media, International Women's Media Foundation, Washington, D. C.

CNn, Expansión. 'Lo que se disputan Carso y Televisa' 21 Febrero. [en línea] Disponible en: http://www.cnnexpansion.com/negocios/2011/ 
02/21/slim-y-televisa-pelea-mercado-22000-mdd. Consulta: 10 de agosto de 2011.

Comisión Federal de Telecomunicaciones. Bases de datos de la industria de la Radio y la Televisión Primer trimestre 2011. México, COFETEL. 2011. Fraser, Nancy. 'Feminism, Capitalism and the Cunning of History', New Left Review, 56 (Mar-Apr), pp. 97-117, 2009.

Gallagher, Margareth. An Unfinished Story: Gender Patterns in Media Employment'. Paris, UNESCO, 1990.

Gómez, Rodrigo. Políticas e industrias audiovisuales en México: apuntes y diagnóstico, Revista Comunicación y Sociedad-Nueva época, 10 (JulioDiciembre), pp. 191-223, 2008.

InTERNATIONAL WOMEN's Media Foundation. Global Report on the Status of Women in the News Media. Washington, D.C., 2011.

Lagarde, Marcela Género y Feminismo. Desarrollo Humano y Democracia, Madrid, horas y HORAs. (2001)

- Los cautiverios de las mujeres: madresposas, monjas, putas, presas y locas. CEIICH/DGEP/FFyL/PUEG UNAM, México, 1990.

Lauer, Nancy Cook (2002). "Studies Show Women's Role in Media Shrinking. Women's eNews", www.womensenews.org/article.cfm/ dyn/aid/915/context/archive (consulta en línea: Junio 18, 2008)

LERNER, Gerda. La creación del patriarcado. Barcelona, Crítica, 1990

Medios Publicitarios Mexicanos. Tarifas y datos, medios audiovisuales. MPM, México, 2011.

MoIA, Marta. El sí de las niñas. Barcelona, Lasal, 1981.

Monroy, Paulina. "La educación en México: cada vez más pobre y más desigual", Contralínea, 28 de febrero de 2010, http://contralinea.info/ 
archivo-revista/index.php/2010/02/28/educacion-en-mexico-cadavez-mas-pobre-y-desigual/ consultado en febrero 10 de 2011.

Ortega, Patricia. Panorama de los medios públicos. Panorama de la comunicación en México 2011. Desafíos para la calidad y la diversidad. México, Amedi, 2011.

RIORDAN, Ellen. Intersections and New Directions: On Feminism and Political Economy in Sex $\mathcal{B}$ Money, Feminism and Political Economy in the Media, eds. Meehan, Eileen \& Riordan, Ellen, University of Minnesota Press, Minneapolis, pp. 3-15, 2002.

SECRETARÍA DE EdUCACIÓN PÚBLICA. Informe nacional sobre Violencia de Género en la Educación Básica en México, México, SEP, 2010.

Secretaría de Gobernación. Padrón Nacional de Medios Impresos de la Secretaría de Gobernación. México, SEGOB, 2011.

SteEves, Leslie y Janet WAsko. "Feminist Theory and Political Economy: Toward a Friendly Alliance" in Sex and Money, Feminism and Political Economy in the Media, eds. Meehan, Eileen \& Riordan, Ellen, University of Minnesota Press, Minneapolis, pp. 16-29, 2002.

Vega Montiel, Aimée. "Las mujeres y el derecho humano a la comunicación: su acceso y participación en la industria mediática”, Revista Mexicana de Ciencias Políticas y Sociales. FCPyS UNAM, 208 (enero-abril), pp. 81-96, 2010.

WASKO, Janet. 'Studying the Political Economy of Media and Information', revista Comunicação e Sociedade, 7, pp. 25-48, 2005.

World Economic Forum (2010). The Global Gender Gap Report 2010, weF, Geneva. 